\title{
An assessment of written patient information provided at the genetic clinic and relating to genetic testing in seven European countries
}

\author{
Celine Lewis ${ }^{\star},{ }^{1}$, Pritti Mehta ${ }^{1}$, Alastair Kent ${ }^{1}$, Heather Skirton ${ }^{2}$ and Domenico Coviello ${ }^{3}$ \\ ${ }^{1}$ Genetic Interest Group, London, UK; ${ }^{2}$ Faculty of Health and Social Work, University of Plymouth, Taunton, UK; \\ ${ }^{3}$ Laboratory of Medical Genetics, Fondazione IRCCS, Maggiore Policlinico, Mangiagalli e Regina Elena, Milan, Italy
}

The aim of this study was to assess the quality of written information for patients and families about genetic testing, from a range of European countries. Written information relating to genetic testing for five conditions was gathered from genetic departments across seven European countries. Written information for each condition from each country was randomly chosen for assessment. Fourteen key issues had been identified by a number of pre-existing tools (in particular the DISCERN-Genetics tool) as being important for inclusion when developing or assessing material relating to genetic testing. Fifty pieces in total were assessed for the inclusion or omission of key issues. Although the majority of information discussed issues relating to the condition including background and effect $(n=48,96 \%)$, treatment and management $(n=37,74 \%)$ and heredity and risk $(n=49,98 \%)$, only half the information discussed where to obtain additional information and support $(n=25,50 \%)$. Less than half the information discussed what happens after the test $(n=15,30 \%)$, patient rights $(n=12,24 \%)$ and shared decision making $(n=12,24)$. Benefits were more likely to be included $(n=41,82 \%)$ than any risks involved $(n=24,48 \%)$. The issue discussed least frequently was the possible psychological and social effects of genetic testing $(n=9,18 \%)$. Pre-written leaflets tended to provide a more comprehensive discussion of the issues surrounding genetic testing than personal letters did and should therefore routinely be available to patients alongside personal letters. Written information should include risks and limitations of testing as well as discussion of the psychological and social aspects of genetic testing.

European Journal of Human Genetics (2007) 15, 1012-1022; doi:10.1038/sj.ejhg.5201874; published online 13 June 2007

Keywords: genetic testing; patient information; assessment; Europe

Introduction

It is integral to the delivery of good quality health care that patients are provided with information that is accurate, accessible and covers a spectrum of issues important to patients and families. This is especially true in an age when

*Correspondence: C Lewis, Eurogentest project, Genetic Interest Group, Unit 4d Leroy House, 436 Essex Road, London N1 3QP, UK.

Tel: + 44207704 3141; Fax: + 44207359 1447;

E-mail: celine@gig.org.uk

Received 11 January 2007; revised 3 May 2007; accepted 15 May 2007; published online 13 June 2007 patients are taking greater interest than ever before in managing their health. ${ }^{1}$ There are numerous sources of health information available for patients and the amount of literature available is growing rapidly. ${ }^{2}$ This is especially true of the internet resources, where an average of $23 \%$ of the population go to access information about health issues. ${ }^{3}$ There has, however, been little evaluation of the accuracy and effectiveness of much of this information ${ }^{4,5}$ and this could potentially lead to patients being given information that is misleading, inaccurate and biased, ${ }^{6}$ thus hindering their ability to make informed decisions. In the context of genetics, while great progress has been made 
on the research front, genetic literacy among the general population is relatively low, ${ }^{7}$ making it imperative that oral information is supported by written material during the counselling process. Used alongside verbal communication, it has been shown to improve patient's satisfaction ${ }^{8,9}$ and knowledge ${ }^{10}$ of complex and sensitive issues. Written information also has a role in allaying patient anxiety ${ }^{11}$ and improving the decision-making process necessary for giving informed consent to genetic testing. ${ }^{12}$ Style, tone and language are also important aspects of written communication in that they can affect the way in which information is understood, and if used effectively can alleviate stress and anxiety. ${ }^{13}$ Leaflets and other written material can therefore play an important part in supplementing and reinforcing information provided by clinicians.

A number of studies have been carried out to evaluate existing written patient information. A recent study ${ }^{14}$ looking at patient information on newborn bloodspot screening found that the majority of leaflets supported the public health agenda by informing parents of the benefits of screening, including the significance of early detection and treatment for these conditions. Few leaflets however supported the informed choice agenda by mentioning either the limitations of screening or choice. A study assessing the readability of materials describing genetic risk for breast cancer found that images used were not sufficiently clear and there were difficulties with word comprehension, in spite of the inclusion of definitions and a glossary. ${ }^{15}$ Another study $^{16}$ conducted in the USA, looking at educational material for patients and practitioners about genetic testing concluded that most materials did not contain basic information about the test itself, for example the purpose or accuracy of the test. Very few materials discussed both the benefits as well as risks of genetic testing. There have, however, been no studies published that address this issue from a European perspective.

This paper reports the findings of a project aimed at assessing a selection of patient material used in Europe, related to genetic testing for a number of conditions for which genetic counselling may be sought. Screening tests that do not provide a definitive result were not included in the study. This research was conducted as part of the Eurogentest project ${ }^{17}$ (www.eurogentest.org), a European Network of Excellence aimed at harmonising genetic testing services across Europe.

\section{Methods}

Owing to the number of countries in Europe, and the practical limitations of the project, it was not feasible to collect data from every European country. Seven countries were identified with an aim to achieving maximum variation in terms of geographical location, health and political systems and genetic service development. These were: the UK, Belgium, Sweden, the Netherlands, Italy, Germany and Poland. Across these seven countries information was gathered concerning genetic testing for five genetic conditions. These were hereditary breast cancer, Duchenne muscular dystrophy, tuberous sclerosis, 22q11 deletion and the connexin 26 alteration. This panel of conditions was chosen because they reflect a range of conditions in terms of inheritance pattern (autosomal dominant, autosomal recessive, X-linked, chromosomal) and age at diagnosis (newborn, childhood and adulthood). Some cause premature death while others are not lifethreatening. The panel includes very rare and more common genetic conditions and the conditions are thought to be equally prevalent across the selected states.

\section{Data collection}

Service providers were identified through a network of key informants (eg clinical geneticists, chairs of genetic societies etc) in each country. A letter was sent to each service provider in each country asking them to participate in the study. Face-to-face interviews were organised with two or three service providers in each state who responded positively to the invitation in order to gather examples of written patient information and to discuss the way in which genetic services are run. This was to provide a context for the study (an overview of the organisation of genetic services across the seven European states can be found in the Eurogentest report ${ }^{18}$ ). Written information was also collected in a number of formats from the same service providers. Providers were asked to forward or reference any material provided to individuals seeking counselling for genetic testing for the conditions previously named. Material was collected in the following formats: personal letters written by a clinician, standard letters which are used as templates for personal letters, leaflets and booklets available directly from the genetic clinic, web-based material provided by the clinician or to which patients would be directed.

\section{Data analysis}

To assess the material gathered, current approaches that exist to write and assess material related to genetic testing were first reviewed. This was carried out through internet and bibliographic database searches (Ovid, Medline, Google) and through discussion with researchers and geneticists working in the field of patient education. Four existing approaches were identified using this method. These were:

(1) DISCERN-Genetics, a tool that guides the production and appraisal of information resources produced for the public on genetic testing. ${ }^{19}$ 
(2) Erfocentrum Guidelines developed to guide the production of information related to genetics on the Erfocentrum website. ${ }^{20}$

(3) An appraisal tool (published in the American Journal of Medical Genetics) developed to analyse pamphlets containing information about genetic testing. ${ }^{16}$

(4) Criteria identified in a leaflet for parents of children with a genetic disorder developed by the Genetic Interest Group. ${ }^{21}$

Each tool presented a number of key issues as being important when developing or assessing material relating to genetic testing. Although these key issues were derived from information for the public, and people will want personal support from genetic specialists in interpreting information about their genetic risk, it is reasonable to suppose the categories of information will be the same. Definitions of genetic testing varied slightly across the tools. While the tool in the American Journal of Medical Genetics excluded newborn screening tests in their definition of genetic testing, the DISCERN tool was developed through the appraisal of information on genetic testing and screening. None of the key issues raised by the tools however were specific to screening and hence all the issues identified were considered relevant to genetic testing in a clinical setting. Each key issue was identified, given a suitable title and tabulated. Care was taken to avoid overlap between issues. Fourteen key issues in total were identified. The key issues were chosen because they addressed themes that were considered important for inclusion in written information for all five conditions. In addition, because the key issues themselves were fairly general, each of them were considered to be of equal importance across the five conditions. For the most part, the titles used by DISCERN-Genetics were adopted. Each key issue was correlated against each tool for an agreement rating (Table 1). Apart from two issues ('what happens after the test' and 'shared decision making'), each issue had been raised by two or more of the tools indicating a high agreement rate among the tools concerning the key issues surrounding genetic testing.

For the purposes of this study, a table of issues was created with a title of the issue and a supporting description of each issue (Table 2). Each description provided examples of the way in which the issue might be presented to the reader. As many statements referred to the same issue, albeit in a slightly different way, care was taken to avoid overlap. However, because each key issue had a fairly wide remit, it was also important that a variety of possible descriptions were used in order to ensure as full an explanation as possible. As the DISCERN tool was the most comprehensive of the four tools, many of the descriptions used were taken directly from this tool. However, we did identify a number of additional descriptions from other sources. This table (Table 2) was used to
Table 1 Agreement rating for key issues relating to genetic testing

\begin{tabular}{|c|c|c|c|c|}
\hline Key theme & DISCERN & Erfo & AJMG & GIG \\
\hline $\begin{array}{l}\text { Background and effect of } \\
\text { condition }\end{array}$ & / & / & / & / \\
\hline Treatment and management & / & / & / & / \\
\hline Heredity and risk & / & / & / & / \\
\hline Patient rights & / & & / & \\
\hline Type of test & / & l & / & l \\
\hline Test procedure & / & l & / & \\
\hline Accuracy of test & I & & / & / \\
\hline What happens after the test & / & & & \\
\hline Shared decision making & / & & & \\
\hline Psychosocial consequences & l & & / & l \\
\hline $\begin{array}{l}\text { Consequences for relatives } \\
\text { and partner }\end{array}$ & I & & / & / \\
\hline Benefits and risks & / & & / & \\
\hline Date and sources & / & / & & \\
\hline $\begin{array}{l}\text { Additional support and } \\
\text { information }\end{array}$ & / & / & & / \\
\hline
\end{tabular}

AJMG, American Journal of Medical Genetics; ${ }^{16}$ DISCERN, DISCERNGenetics; ${ }^{19}$ Erfo, Erfocentrum; ${ }^{20} \mathrm{GIG}$, Genetic Interest Group. ${ }^{21}$

guide scoring of each piece of patient information that was assessed.

When the written patient material was collected, those items that were extremely brief were excluded from the assessment. Where possible, two pieces of written material for each condition from each country were randomly chosen. Those that were not in English were translated by a professional translation service experienced in working with health-related materials. Where we were unable to collect two pieces of material on a condition from a specific country, we assessed only one. Unfortunately, in a few cases, we were unable to collect material for a particular condition, from a particular country. This may either have been because the departments visited did not perform the particular test, or written information had not been produced about it.

Fifty pieces of information were assessed in total. Of these 50 pieces, 25 were personal letters, 23 were prewritten leaflets and two were standard letters. Each piece was assessed for the presence or absence of 14 key issues that had been identified by the four tools. A statement fitting any part of the description was counted as a presence of the key issue. In order for a piece of information to score on the issue 'benefits and risks', the piece had to present both a harm (risk or limitation of testing) and a benefit. In addition to scoring content of the written material, the use of medical terms, which may not be understood by lay readers was taken into account.

\section{Results}

The amount of information provided to patients and families varied tremendously with information ranging 
Table 2 Table of key themes and descriptions used to assess written material relating to genetic testing

$$
\text { Criteria from DISCERN-Genetics }{ }^{19}
$$

(Copyright University of Oxford 2005) www.discern-genetics.org

Additional descriptions (from $A / M G^{16} \mathrm{GIG}^{21}$ Erfocentrum $^{20}$ and independent research ${ }^{50}$ )

Background and Symptoms, occurrence. A description between being a carrier and effect of condition having the condition

Treatment and
management

Heredity and risk (modified from the original question 'Is risk explained in simple terms?') Test procedure

Accuracy of test

What happens after the test Shared decision making

Psychosocial consequences

Consequences for relatives and partner

Date and sources

Additional support and information

Whether any geographical differences in service provision are outlined, for example test availability (taken from the DISCERN question 'Is information provided on local availability of services and test performance?) the condition with the faulty gene compared with the risk if one does not have the faulty gene Chance that the condition will not develop.

Safety/risk of procedure. If it hurts

An acknowledgement of any limitations of testing such as an explanation of how tests fail due to either human or laboratory error. An explanation of false positive and false negative test result. that a repeat test may be needed and why

Things to discuss with family, friends, and health professionals

The various emotional and social consequences that might be anxiety). That a range of emotions are possible and normal. Possible discrimination arising from test results, for example, employment and insurance (taken from the DISCERN question 'Are issues of discrimination discussed?')

What an increased risk means to person being tested and their family. That different people have different reactions. That misattributed paternity may be discovered

Name and date of publication and any revision
Cause (at genetic, chromosome, cellular, organ level ${ }^{20}$ development ${ }^{20}$ characteristics 20 prognosis, 21 diagnosis. ${ }^{20,21}$ Any other name the condition might be known as 20 Strategies for prevention. ${ }^{16}$ Whether there is a cure. ${ }^{18}$ Other medical management options ${ }^{16,21}$

Why the reader might be appropriate for testing. ${ }^{16}$ Reproductive risk. ${ }^{16,21}$ Risk develoning to why the reader might be at specific risk. The risk Any evidence of local variations in laboratory result. An explanation

Follow-up procedures. Who gives results and how they are received experienced, both positive and negative (such as relief or increased emotional consequences ${ }^{50}$
Where and how it is performed $?^{50}$ Whether it has to be paid for privately or if it is free ${ }^{16}$

Specificity. ${ }^{16}$ An explanation of false positive and false negative test result ${ }^{16}$

Where the sample is sent. ${ }^{50}$ Waiting time for results ${ }^{50}$

Whether any benefits can be claimed ${ }^{21}$

That the family may experience a range of

References of experts or organisations quoted, a reference to a current guideline on which the information is based ${ }^{50}$

Such as details of local services, support organisations other sources of information, other relevant health professionals $^{21}$

Additional descriptions (taken from AMJG, ${ }^{16} \mathrm{GIG}^{21}{ }^{21}$ Erfocentrum, ${ }^{20}$ March of Dimes ${ }^{51}$ and Independent Research ${ }^{50}$ )

Type of test

Patient rights

The type of test; that is carrier, diagnostic, prenatal, predictive, newborn screening ${ }^{16}$

That testing is voluntary, about the need for informed consent, that results are confidential, that the patient can specify to whom results can be disclosed ${ }^{16}$

Benefits and risks Whether the information presents statements that discuss both the risks/limitations of genetic testing, as well as the benefits

Benefits: for example, may lead to (early) diagnosis, may lead to disease prevention or treatment, can help guide reproductive decision-making, may provide psychological benefits, may be able to claim societal benefits after confirmation of a diagnosis 51

Risks and limitations: for example, may cause emotional and psychological difficulties, such as anger, guilt, anxiety, strained relationships etc, may put one in a position where difficult decisions have to be made, may identify other 'at risk' family members without their consent, may cause discrimination in insurance, expense, may not be able to reach a diagnosis, there may be no intervention or treatment available, may not be able to provide exact risk assessment, negative test results may not guarantee patient will not develop condition ${ }^{51}$

from half an A4 side to a small booklet 50 pages long. The majority of material discussed issues relating to the condition (Figure 1), including background and effect $(n=48,96 \%)$, treatment and management $(n=37,74 \%)$ heredity and risk ( $n=49,98 \%)$ and the type of test $(n=46$, $92 \%)$. However, less than half discussed key issues such as what happens after the test $(n=15,30 \%)$, shared decision making $(n=12,24 \%)$, patient rights $(n=12,24 \%)$ and a 


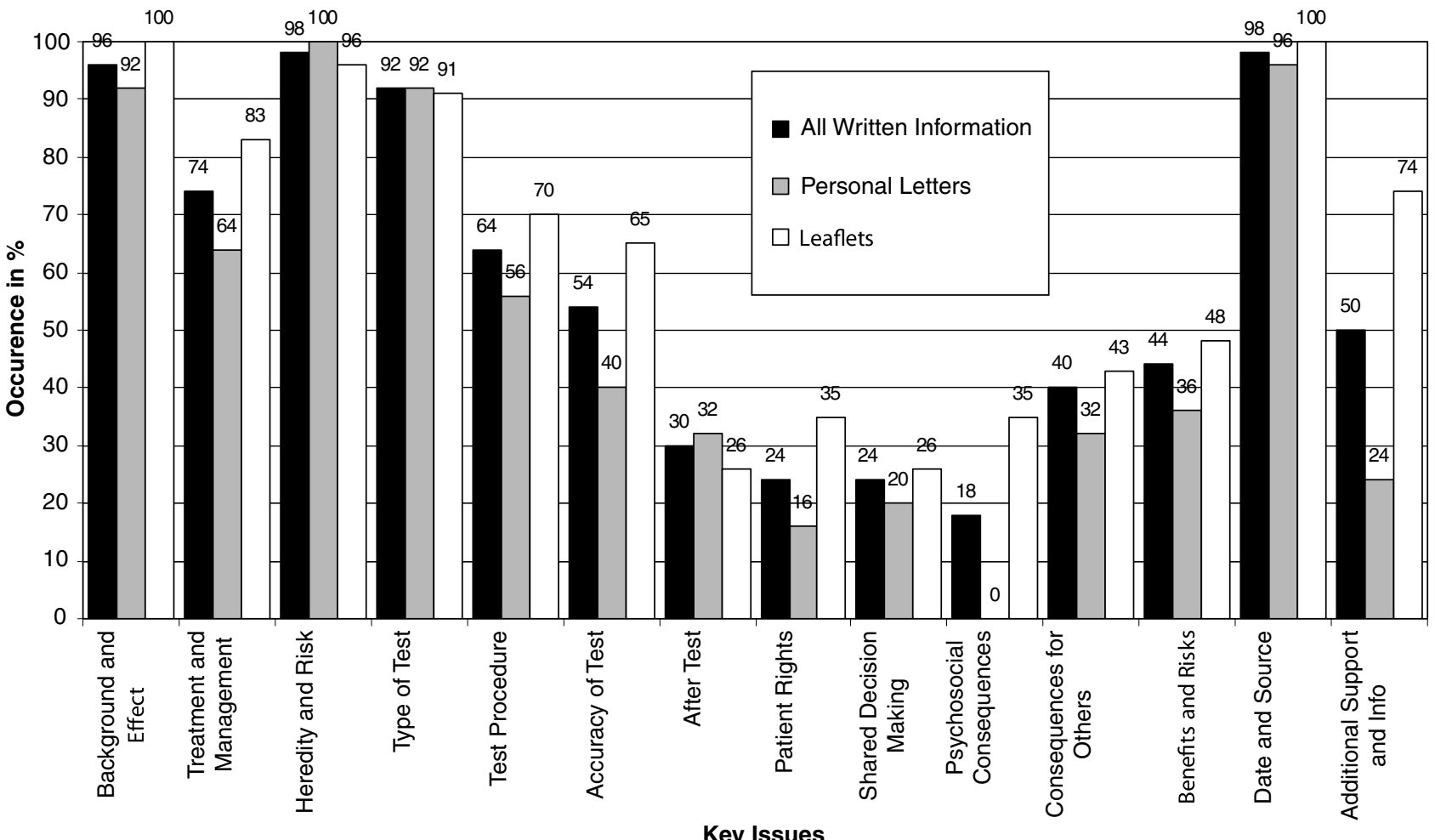

Figure 1 Frequency of key themes in written material relating to genetic testing.

discussion of the benefits as well as potential risks of genetic testing $(n=22,44 \%)$. Only half discussed where to get additional information and support from $(n=25,50 \%)$. Benefits of genetic testing were more likely to be included $(n=41,82 \%)$ than any risks involved $(n=24,48 \%)$. The topic discussed least was the possible psychological and social effects of genetic testing $(n=9,18 \%)$.

\section{Letters versus leaflets}

When the content of personal letters was compared with the content of pre-written leaflets (Figure 1), it was found that a greater number of key topics were discussed in the leaflets. In particular, pre-written leaflets tended to include more information about the accuracy of the test and information related to patient rights. Pre-written leaflets were also more likely to discuss both the benefits and risks of genetic testing. There was no discussion of the possible psychosocial effects of genetic testing in any of the personal letters assessed. Only a small number of personal letters provided information about additional support organisations and information services.

\section{Psychological and social issues}

Psychological and social issues including patient rights, shared decision making and psychosocial consequences, were more frequently discussed in information relating to hereditary breast cancer than the other four conditions. Of the four pieces that scored on every key issue, all of them related to hereditary breast cancer, and all were either in leaflet or brochure form (two were developed by genetic departments, and two were developed by patient organisations).

\section{Benefits and risks}

Of those pieces that did discuss both a benefit and a risk of genetic testing, a large number (10/22) related to hereditary breast cancer. The following Belgian leaflet is one example of a leaflet that presents both a benefit and a risk of genetic testing:

'Women that are a carrier of an abnormality in the BRCA1 or BRCA2 gene and therefore have a strongly increased risk of developing breast and/or ovarian cancer must be kept under very close medical observation. An early discovery increases the chances of recovery [benefit]........... The decision to have a predictive test carried out can have large consequences and be very emotional [risk]. It is very important to have people who ask to have these tests carried out, treated and supported by a multidisciplinary team. This team must pay special attention to all the decisions etc that a possible confrontation 
with hereditary breast cancer can involve.' (KU Leuven genetic department)

Benefits that were frequently cited included that genetic testing could lead to a diagnosis, disease prevention or treatment. Risks and limitations that were frequently discussed were that testing could be very emotional, it may be a time-consuming process, and that not all the mutations that cause the condition are known.

\section{Comparing written material for different conditions}

The quality of written patient information varied across conditions (Table 3). The frequency of discussion around 'patient rights', that is, the discussion of issues including that testing is voluntary, and that decisions should be consistent with the decision-maker's values, varied considerably across the five conditions. It was discussed in $67 \%$ of the material about hereditary breast cancer, in $17 \%$ of the material about the connexin 26 alteration and in only $8 \%$ of the information about Duchenne muscular dystrophy. When the issue was discussed, it was carried out far more overtly in certain cases than in others. For example in one booklet assessed, the issue that testing is voluntary was made very explicit:

'This is your decision to make and can be very difficult. Your genetic counsellor can talk through all the issues with you, and other people can help you to deal with the emotional issues that may arise' (UK breast cancer booklet, CancerBACUP).

In another piece, the fact that testing is voluntary was implied far more implicitly:
'The test is only offered to people, in whose family wellfounded evidence of inherited breast cancer is to be found.' (German letter about hereditary breast cancer).

Information on the more prevalent genetic conditions (ie hereditary breast cancer) was found to be of a higher quality (ie discussed a greater number of key issues) than information on the rarer conditions. On average, the 14 key issues were discussed in $81 \%$ of the material on breast cancer but in only $44 \%$ of material on the connexin 26 alteration. Some of the most notable findings were that none of the material on 22q11 deletion, connexin 26 alteration or tuberous sclerosis discussed psychosocial consequences of genetic testing and none of the material on the connexin 26 alteration discussed where to access additional support and information from (Table 3 ).

\section{Comparing material from different countries}

The frequency of discussion for each of the key themes was similar across the seven countries for the majority of key themes (Table 4). However, there were some notable differences in certain areas including test accuracy, shared decision making, benefits and risks and additional support and information.

\section{Risk}

Some interesting stylistic variations were found when assessing the material related to risk, as the following two examples show:

'It has been observed that women carrying BRCA1 mutations have increased risk of developing breast and ovarian cancer with respect to other women from

Table 3 Frequency of key themes relating to genetic testing per condition

\begin{tabular}{|c|c|c|c|c|c|c|}
\hline & $H B C^{\mathrm{a}}$ & $D M D^{\mathrm{b}}$ & $\mathrm{C} 26^{\mathrm{C}}$ & $22 q 11^{\mathrm{d}}$ & $T S^{\mathrm{e}}$ & Total \\
\hline Background and effect & $11 / 12$ & $12 / 13$ & $6 / 6$ & $11 / 11$ & $8 / 8$ & $48 / 50$ \\
\hline Treatment and management & $12 / 12$ & $9 / 13$ & $2 / 6$ & $8 / 11$ & $6 / 8$ & $37 / 50$ \\
\hline Heredity and risk & $12 / 12$ & $13 / 13$ & $6 / 6$ & $11 / 11$ & $7 / 8$ & $49 / 50$ \\
\hline Patient rights & $8 / 12$ & $1 / 13$ & $1 / 6$ & $1 / 11$ & $1 / 8$ & $12 / 50$ \\
\hline Type of test & $11 / 12$ & $13 / 13$ & $5 / 6$ & $11 / 11$ & $6 / 8$ & $46 / 50$ \\
\hline Test procedure & $10 / 12$ & $11 / 13$ & $1 / 6$ & $6 / 11$ & $4 / 8$ & $32 / 50$ \\
\hline Accuracy of test & $9 / 12$ & $6 / 13$ & $3 / 6$ & $6 / 11$ & $3 / 8$ & $27 / 50$ \\
\hline After test & $8 / 12$ & $4 / 13$ & $2 / 6$ & $0 / 11$ & $1 / 8$ & $15 / 50$ \\
\hline Shared decision making & $7 / 12$ & $1 / 13$ & $3 / 6$ & $0 / 11$ & $1 / 8$ & $12 / 50$ \\
\hline Psychosocial consequences & $8 / 12$ & $1 / 13$ & $0 / 6$ & $0 / 11$ & $0 / 8$ & $9 / 50$ \\
\hline Consequences for others & $10 / 12$ & $3 / 13$ & $1 / 6$ & $4 / 11$ & $2 / 8$ & $20 / 50$ \\
\hline Benefits and risks & $10 / 12$ & $6 / 13$ & $1 / 6$ & $4 / 11$ & $1 / 8$ & $22 / 50$ \\
\hline Date and source & $12 / 12$ & $13 / 13$ & $6 / 6$ & $10 / 11$ & $8 / 8$ & $49 / 50$ \\
\hline Additional support and information & $8 / 12$ & $6 / 13$ & $0 / 6$ & $6 / 11$ & $5 / 8$ & $25 / 50$ \\
\hline Total & $\begin{array}{c}136 / 168 \\
81 \%\end{array}$ & $\begin{array}{c}99 / 182 \\
54 \%\end{array}$ & $\begin{array}{c}37 / 84 \\
44 \%\end{array}$ & $\begin{array}{c}78 / 154 \\
51 \%\end{array}$ & $\begin{array}{c}53 / 112 \\
47 \%\end{array}$ & \\
\hline
\end{tabular}

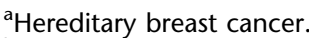

${ }^{\mathrm{b}}$ Duchenne muscular dystrophy.

${ }^{c}$ Connexin 26 alteration.

d 22q11 deletion.

eTuberous sclerosis. 
Table 4 Frequency of key themes relating to genetic testing per country

\begin{tabular}{|c|c|c|c|c|c|c|c|c|}
\hline & $U K$ & Netherlands & Belgium & Sweden & Italy & Germany & Poland & Total \\
\hline Treatment and management & $7 / 8$ & $6 / 8$ & $3 / 5$ & $6 / 7$ & $6 / 7$ & $7 / 10$ & $2 / 5$ & $37 / 50$ \\
\hline Type of test & $8 / 8$ & $7 / 8$ & $4 / 5$ & $6 / 7$ & $7 / 7$ & $10 / 10$ & $4 / 5$ & $46 / 50$ \\
\hline Test procedure & $7 / 8$ & $4 / 8$ & $2 / 5$ & $5 / 7$ & $3 / 7$ & $7 / 10$ & $4 / 5$ & $32 / 50$ \\
\hline Accuracy of test & $8 / 8$ & $3 / 8$ & $2 / 5$ & $2 / 7$ & $3 / 7$ & $5 / 10$ & $4 / 5$ & $27 / 50$ \\
\hline Psychosocial consequences & $2 / 8$ & $2 / 8$ & $1 / 5$ & $2 / 7$ & $0 / 7$ & $1 / 10$ & $1 / 5$ & $9 / 50$ \\
\hline Consequences for others & $4 / 8$ & $3 / 8$ & $2 / 5$ & $4 / 7$ & $1 / 7$ & $4 / 10$ & $2 / 5$ & $20 / 50$ \\
\hline Benefits and risks & $6 / 8$ & $4 / 8$ & $2 / 5$ & $1 / 7$ & $3 / 7$ & $5 / 10$ & $1 / 5$ & $22 / 50$ \\
\hline Date and source & $8 / 8$ & $8 / 8$ & $5 / 5$ & $7 / 7$ & $7 / 7$ & $10 / 10$ & $4 / 5$ & $49 / 50$ \\
\hline Additional support and information & $4 / 8$ & $8 / 8$ & $2 / 5$ & $5 / 7$ & $0 / 7$ & $5 / 10$ & $1 / 5$ & $25 / 50$ \\
\hline Total & $\begin{array}{c}79 / 112 \\
71 \%\end{array}$ & $\begin{array}{c}64 / 112 \\
57 \%\end{array}$ & $\begin{array}{c}34 / 70 \\
49 \%\end{array}$ & $\begin{array}{c}57 / 98 \\
58 \%\end{array}$ & $\begin{array}{c}48 / 98 \\
49 \%\end{array}$ & $\begin{array}{c}86 / 140 \\
61 \%\end{array}$ & $\begin{array}{c}35 / 70 \\
50 \%\end{array}$ & \\
\hline
\end{tabular}

the population at large........This assertion is not the same as saying that carriers of a hereditary BRCA1 mutation are sick, or destined to become sick: considering one's entire lifespan a large proportion of the women carrying these mutations will not develop breast tumours....From available research data, it may be said that out of 100 women with the BRCA1 mutation, 15-40 will not develop breast tumours within their expected lifetime (70 years) and that 5070 women will not develop breast tumours prior to the age of 50.' '(Italian letter, hereditary breast cancer)' 'Presence of the mutation in the BRCA1 and/or BRCA2 gene indicates a significant predisposition to breast and ovarian cancer........Women up to 70 years old with a mutation in these genes have a more that $80 \%$ risk of falling ill with breast cancer, and $40 \%$ risk of developing an ovarian tumour.' (Polish leaflet about hereditary breast cancer, Amazonki patient association)

The first piece, translated from Italian, explains risk in terms of the chance the condition will not develop, whereas the Polish piece discusses risk in terms of the chance the condition will develop. Furthermore, the tones within the two pieces are quite different. The Italian letter comes across as quite reassuring and friendly, whereas the language in the Polish leaflet is more scientific ('significant predisposition') and matter of fact.

The level of detail provided within the material varied tremendously, especially around issues relating to the test. Although a few pieces went into great detail about the test procedure, others merely mentioned that a blood sample would be taken, and a 'genetic examination' performed. This can be seen from the two examples below:

'In about $25 \%$ of patients the 22q11 deletion is visible when the chromosomes are looked at under the microscope. However, in about $75 \%$ of patients the deletion is submicroscopic, which means that although you cannot see the missing material under a microscope, you can prove that the piece is missing by using a special DNA test called FISH (fluorescent in situ hybridisation). If someone has a 22q11 deletion then when FISH studies are carried out rather than seeing two fluorescent signals (one on each chromosome $22 \mathrm{q} 11$ region) only one fluorescent signal is seen.' (22q11 leaflet, North West Thames Regional Genetics Service, UK)

'If there is a suspicion of the diagnosis (22q11 deletion) then a genetic examination is needed to confirm or exclude the diagnosis. This requires a tube of blood from the child. The genetic examination can demonstrate whether there is a micro deletion on chromosome 22.' (Dutch 22q11 booklet, Federatie van Ouderverenigingen)

\section{Discussion}

Overall, every piece of material assessed included discussion of some of the issues considered important when discussing genetic testing. Information was far more likely to discuss hard, factual information related to the condition and the test, than the more qualitative, experiencebased information related to the psychological and social implications of genetic testing and this is a concern since studies have shown that patients do require psychosocial information. $^{22}$ One reason for this may be that the acceptability and expectation of writing about psychosocial issues may vary considerably across the various cultures in the selected states.

The reason that personal letters were found to be less comprehensive than pre-written leaflets is likely to stem from a number of causes. The first may be the shortage of 
resources and time experienced by genetic services. ${ }^{23}$ Writing personal letters is a time-consuming process and clinicians may feel constrained to write only about those issues they consider most important. They may also be sensitive to issues of confidentiality since clinical letters are often copied to other practitioners. Pre-written leaflets can be assessed by patients and professionals during the development stage to ensure they cover all the key issues. In addition, pre-written leaflets are often prepared by patient groups and are hence patient-driven. They may therefore be more likely to tackle the issues important to patients and families.

It is important to note that at some genetic clinics, patient leaflets (either developed by the clinic or by patient organisations) were provided to patients or were freely available for patients to take. In both Belgium and the Netherlands, one clinic provided us with a leaflet on $22 \mathrm{q} 11$ deletion and a leaflet on hereditary breast cancer. Genetic clinics in the Netherlands also have close links with the Erfocentrum organisation (who have a website providing patients with information about genetic conditions) and we were often provided with the organisation's details during the face-to-face interviews. In Germany, a brochure from a 22q11 patient organisation was enclosed within a personal letter, and details for the tuberous sclerosis association were provided in another. In the UK, one particular genetic clinic had developed numerous leaflets related to all the genetic conditions looked at, that patients could freely access. Therefore, in some cases the personal letters were provided in combination with other written materials or with referral to information on the internet. This might theoretically compensate for some of the observed shortcomings in the personal letters.

Information that related to hereditary breast cancer scored far better during the assessment than information concerning the other four conditions; in particular relating to psychosocial consequences and patient rights. There has been much research performed on the information needs of hereditary breast cancer patients owing to its high prevalence in the European population..$^{24-27}$ As previously discussed, a number of genetic clinics were found to have developed pre-written leaflets due to the high number of people counselled about this condition. ${ }^{28}$ In addition, a number of high-profile cancer charities across Europe are key players in developing patient information and consulting with patients during the development stages. Hence, the information they produce is likely to reflect the issues that are of concern to patients and families.

Psychological and social issues were not readily discussed outside of information related to hereditary breast cancer, despite a body of research relating to the social and psychological problems experienced when receiving a diagnosis for the rarer genetic conditions. ${ }^{29-32}$ Testing positive as a carrier may result in feelings of guilt or anger. $^{33,34}$ Genetic testing might also inadvertently dis- close information about relatives or parentage, or cause complications when buying health and life insurance. A number of studies have also been conducted on the psychosocial effects of testing specifically for the rarer conditions that were the focus of this study. Research looking at X-linked and autosomal recessive conditions including Duchenne muscular dystrophy, found that mothers of affected children were likely to feel guilt and blame themselves for the child's condition. ${ }^{35,36}$ A study looking at the behaviour of children with 22q11 deletion found that there was a significant risk of psychiatric problems in childhood as well as in adolescence and early adulthood. ${ }^{37}$ Approximately half of individuals diagnosed with tuberous sclerosis complex present with global intellectual impairment and psychiatric disorders. ${ }^{38}$ Yet, even though much research has been carried out in this area, the fact that there was a lack of psychosocial information provided in written material concerning these conditions suggests that much of this research has not yet been translated into practice.

Clinicians may believe it is outside their remit to provide information about social and psychological issues, considering that it is the responsibility of patient organisations or social services. Yet the International Society of Nurses in Genetics states that one of the roles of genetic nurses is to 'provide genetic information and psychosocial support to individuals and families'. ${ }^{39}$ The National Coalition for Health Professional Education in Genetics states that each health-care professional should at a minimum be able to 'understand the social and psychological implications of genetic services'. 40 The UK document on genetics competences for nurses (Fit for Practice in the Genetics Era) states that the competent practitioner should 'demonstrate a knowledge and understanding of the utility and limitations of genetic testing and information, including the potential physical and/or psychosocial consequences of genetic information for individuals, family members and communities' ${ }^{41}$

Less than half of the material discussed both a benefit and a risk of genetic testing. Although many leaflets and letters discussed at least one potential benefit of genetic testing, information was far less forthcoming about the possible risks and limitations. Yet the benefits, limitations and risks of genetic testing are well documented. Benefits include providing certainty for patients, ${ }^{42}$ providing information for relatives ${ }^{43}$ and informing clinical management. Risks and limitations are cited as including mental distress, ${ }^{44}$ inappropriate reassurance if negative $^{45}$ and the fact that interventions may not be available. ${ }^{46}$ However, the general trend relating to patient information has always been to improve health care through early diagnosis and treatment, hence practitioners might be more inclined to present the benefits as opposed to the potential risks. There might also be a desire not to 'worry' patients through the discussion of potential 
risks and that informed choice is a relatively new phenomenon. ${ }^{47,48}$

Only half the written information assessed discussed where to obtain additional information, and how to contact support services and patient groups. This might be because additional information (such as complementary leaflets or patient information websites) may not exist in the patient's own language, or the clinician might be unaware of it. Alternatively, the clinician may feel that he or she have given the patient and family all the information and support that is necessary. In some cases, additional support services or patient organisations may not exist. This is an area that requires further exploration and investigation.

\section{Strengths and limitations of study}

At the time of writing, no other study could be found that compared written information from across Europe for a range of genetic conditions. Every effort was made to ensure that language limitations were kept to a minimum by using a professional translation service with experience translating health information. Information was translated by various translators, so it is possible that the quality of the translation is not uniform.

Owing to resource limitations, only a certain amount of information gathered could be translated and assessed. We are unable to comment on the quality of information that was not translated. Any statement fitting any part of the description of the key themes was counted as a presence of that theme; therefore, the results do not indicate how complete or accurate the information actually is. Although it was unlikely items were missed, it may have also meant the assessment was over generous. We cannot determine the total content of information provided to patients by clinicians because there will be much information that is given orally, which we did not assess. However, it is important to remember that much oral information will be forgotten, ${ }^{49}$ and patients and families cannot be expected to retain what is often complicated and upsetting information, given under stressful circumstances.

\section{Further work}

In view of the key findings from this research, unit 6 of the Eurogentest project ('Patient and Professional Education') will be working toward a number of objectives over the next 3 years.

(1) The development of a set of recommended key issues for inclusion in written patient information related to genetic testing.

(2) The development of general information leaflets for patients and families. These will cover key issues related to genetics including: the basic biological function of genes, chromosomes etc; inheritance patterns and risk; information about the various types of genetic tests available and their potential benefits, limitations and risks. We will also be developing a 'Frequently Asked Questions' leaflet. This information will be developed with the help of professionals, patients and families to ensure that it is accessible, informative and discusses those issues that are important to key stakeholders. Where appropriate, existing information that has already been developed will be utilised.

(3) Translation of the leaflets into a number of European languages. Leaflets will first be checked with professionals in those countries to ensure information is culturally and locally specific.

(4) Dissemination of the leaflets in print and online through genetic clinics, patient groups and national societies of human genetics.

(5) The research highlights that gaps exist in service provision, in particular the lack of attention paid to discussion of the psychosocial impact of genetic testing on patients and families for the rare inherited conditions. Consensus around which health or social care professional should provide this information is needed and discussion will take place on this specific issue with both patient groups and health professionals from across Europe.

\section{Conclusion}

The results of the assessment provide some interesting insights into the current quality of written patient information; in particular, it highlights those issues that are being repeatedly omitted by information providers. The key recommendations are as follows:

- pre-written leaflets tend to provide a more comprehensive discussion of the issues surrounding genetic testing than personal letters do and should therefore routinely be available to patients;

- where pre-written leaflets are available, these should routinely be provided along with personal letters;

- written information should include risks and limitations of testing where these exist;

- written information should include discussion of the psychological and social aspects of genetic testing;

- those writing information leaflets should consider for inclusion each of the key themes identified and listed in Table 2.

There has however been demand in recent years to improve the quality of written patient information. We live in an increasingly legalistic climate where clinicians are under growing pressure to ensure realistic expectations of medical procedures and treatments. Patients and families 
take more interest in their health care than ever before, thus there is an increasing pressure on clinicians and other information sources to provide patients with ever more detailed and informative information. With these factors in mind, we are hopefully moving toward a climate in which good quality information becomes more necessary, and more readily available.

\section{References}

1 Coulter AJ: Partnership with patients: the pros and cons of shared clinical decision making. Health Serv Res Policy 1997; 2: 112-121.

2 Gann B: Consumer health information in the year 2000. Association for Information Managers 1996; 48: 241-245.

3 European Opinion Research Group: European Union citizens and sources of information about health.2003 http://europa.eu.int/ comm/health/ph_information/documents/eb_58_en.pdf.

4 Charnock D, Shepperd S, Needham G, Gann R: DISCERN: an instrument for judging the quality of written consumer health information on treatment choices. J Epidemiol Community Health 1999; 53: 105-111.

5 Meredith P, Emberton M, Wood C: New directions in information for patients. BMJ 1995; 311: 4-5.

6 Benigeri M, Pluye P: Shortcomings of health information on the internet. Health Promot Int 2003; 18: 381-386.

7 Skirton H, Eiser C: Discovering and addressing the client's lay construct of genetic disease: an important aspect of genetic healthcare? Res Theory Nurs Pract 2003; 17: 339-352.

8 Cullbertson V, Arthur T, Rhodes P, Rhodes R: Consumer preferences for verbal and written medication information. DICP 1998; 22: 390-396

9 Mancini J, Nogues C, Adenis C et al: Impact of an information booklet on satisfaction and decision-making about BRCA genetic testing. Eur J Cancer 2006; 42: 871-881.

10 Baker D, Roberts D, Newcombe R, Fox K: Evaluation of drug information for cardiology patients. Br J Clin Pharmacol 1991; 31: $525-531$

11 Laine L, Shulman R, Bartholomew K, Gardner P, Reed T, Cole S: An educational booklet diminishes anxiety in parents whose children receive total parental nutrition. Am J Dis Child 1989; 143: $374-377$.

12 Mancini J, Nogues C, Adenis C et al: Impact of an information booklet on satisfaction, and decision-making about BRCA genetic testing. Eur J Cancer 2006; 42: 871-881.

13 Cope C, Lyons A, Donovan V, Rylance M, Kilby M: Providing letters and audiotapes to supplement a prenatal diagnostic consultation: effects on later distress and recall. Prenat Diagn 2003; 23: 1060-1067.

14 Hargreaves K, Stewart R, Oliver S: Newborn screening information supports public health more than informed choice. Health Educ J 2005; 64: 110-119.

15 Thompson HS, Wahl E, Fatone A, Brown K, Kwate NO, Valdimarsdottir $\mathrm{H}$ : Enhancing the readability of materials describing genetic risk for breast cancer. Cancer Control 2004; 11: $245-253$.

16 Cho MK, Arruda M, Holtzman NA: Education material about genetic tests; does it provide key information for patients and practitioners? Am J Med Genet 1997; 73: 314-320.

17 Cassiman J: Eurogentest - a European network of excellence aimed at harmonizing genetic testing services. Eur J Hum Genet 2005; 13: 1103-1105.

$18 \mathrm{http} / / /$ en.eurogentest.org/files/public/unit6/InterimReport.pdf p13.

19 Shepperd S, Farndon P, Grainge V et al: DISCERN-Genetics: quality criteria for information on genetic testing. Eur J Hum Genet 2006; 14: 1179-1188.

20 Wits-Douw M: Erfocentrum guidelines for developing and writing patient information on the website (www.erfelijkheid.nl).
21 Genetic Interest Group, Angelman Syndrome Support Group, Cri Du Syndrome Support Group publication: Your child has a genetic disorder: What do you need to know and from whom? (www.gig.org.uk).

22 Josephson U, Wickman M, Sandelin K: Initial experiences of women from hereditary breast cancer families after bilateral prophylactic mastectomy: a retrospective study. Eur J Surg Oncol 2000; 26: 351-356.

23 Donnai D: Genetic services. Clin Genet 2002; 61: 1-6.

24 Metcalfe K, Liede A, Trinkaus M, Hanna D, Narod SA: An evaluation of needs of female BRCA1 and BRCA2 carriers undergoing genetic counselling. J Med Gen 2000; 37: 866-874.

25 Eccles DM, Evans DG, Mackay J: Guidelines for a genetic risk based approach to advising women with a family history of breast cancer. J Med Genet 2000; 37: 203-209.

26 Gray J, Brain K, Norman P. et al: A model protocol evaluating the introduction of genetic assessment for women with a family history of breast cancer. J Med Genet 2000; 192-196.

27 Schneider KA: Genetic counselling for BRCA1/BRCA2 testing. Genet Test 1997; 1: 91-98.

28 Wonderling D, Hopwood P, Cull A et al: A descriptive study of UK cancer genetic services: an emerging clinical response to the new genetics. Br J Cancer 2001; 85: 166-170.

29 Hamilton RJ, Bowers BJ, Williams JK: Disclosing genetic test results to family members. J Nurs Scholarsh 2005; 37: 18-24.

30 Smith JA, Brewer HM, Eatough V, Stanley CA, Glendinning NW, Quarell OW: The personal experience of juvenile Huntington's disease: an interpretative phenomenological analysis of parents' accounts of the primary features of a rare genetic condition. Clin Genet 2006; 69: 486-496.

31 Arnold A, McEntagart M, Younger DS: Psychosocial issues that face patients with Charcot-Marie-Tooth disease; the role of genetic counselling. J Genet Couns 2005; 14: 307-318.

32 Skirton H: Parental experience of a pediatric genetic referral. Matern Child Nurs 2006; 31.

33 Bostrom K, Ahlstrom G: Living with a hereditary disease: persons with muscular dystrophy and their next of kin. Am J Med Genet 2005; 136: 17-24.

34 Fanos J, Johnson J: Perception of carrier status by cystic fibrosis siblings. Am J Hum Genet 1995; 57: 431-438.

35 James CA, Hadley DW, Holtzman NA, Winkelstein JA: How does the mode of inheritance of a genetic condition influence families? A study of guilt, blame, stigma, and understanding of inheritance and reproductive risks in families with $\mathrm{x}$-linked and autosomal recessive diseases. Genet Med 2006; 8: 234-242.

36 Reid DT, Renwick RM: Relating familial stress to the psychosocial adjustment of adolescents with Duchenne muscular dystrophy. Int J Rehabil Res 2001; 24: 83-93.

37 Swillen A, Devriendt K, Legius E et al: The behavioural phenotype in velo-cardio-facial syndrome: from infancy to adolescence. Genet Couns 1999; 10: 79-88.

38 Prather P, de Vries PJ: Behavioral cognitive aspects of tuberous sclerosis complex. J Child Neurol 2004; 19: 666-674.

39 ISONG website: what is a genetic nurse? 3/11/03 http:// www.isong.org/about/index.cfm.

40 NCHPEG website; core competences in genetics essential for all healthcare professionals http://www.nchpeg.org/core/Corecomps2005.pdf.

41 Genomics Policy Unit, University of Glamorgan and the Medical Genetics Service for Wales, University Hospital of Wales; Fit for Practice in the Genetics Era; Report to the Department of Health NHS Genetics Team December 2003, Core Standard Statement 5 www.glam.ac.uk/socschool/research/gpu/FinalReport.pdf.

42 Skirton S: Assessing the need for certainty in users of a clinical genetic health service. J Adv Nurs 2006; 55: 151-158.

43 Fulda K, Lykens K: Ethical issues in predictive genetic testing: a public health perspective. J Med Ethics 2006; 32: 143-147.

44 Meiser B, Mitchell PB, McGirr H et al: Implications of genetic risk information in families with a high density of bipolar. Soc Sci Med 2005; 60: 109-118. 
45 McPherson E: Genetic diagnosis and testing in clinical practice. Clin Med Res 2006; 4: 123-129.

46 Thomas S: Society and ethics - the genetics of disease. Curr Opin Gen Dev 2004; 14: 87-91.

47 Stiratt G, Gill R: Autonomy in Medical Ethics after O'Niell. J Med Ethics 2005; 31: 127-130.

48 Mallardi V: The origin of informed consent. Acta Otorhinolaryngol Ital 2005; 25: 312-327.
49 Hopwood P, Howell A, Lalloo F, Evans G: Do women understand the odds? Risk perception and recall of risk information in women with a family history of breast cancer. Community Genet 2003; 6: 214-223.

50 Independent research conducted with the help of breakthrough breast Cancer.

51 March of Dimes: 'Genetics and Your Practice - Benefits, Risks, Limitations of Genetic Testing' http://www.marchofdimes.com/. 